\title{
The Effect of Prolonged Time of Tablet Usage on Postural Alignment in Children
}

\author{
Marwa M. Ibrahim ${ }^{1}$ and Nadia L. Radwan,** \\ ${ }^{1}$ Assiatant professor, Department of Physical Therapy For Growth and Development Disorders in Children and Its Surgery, Faculty of \\ Physical Therapy, Cairo University, Giza, Egypt \\ ${ }^{1}$ Assisstant Professor, Department of Physical Therapy and Health Rehabilitation, College of Applied Medical Sciences, Prince Sattam \\ bin Abdulaziz University, Saudi Arabia \\ ${ }^{2} \mathrm{Ph} . \mathrm{D}$, Department of Biomechanics, Faculty of Physical Therapy, Cairo University \\ Giza, Egypt \\ ${ }^{*}$ Corresponding author's email: nadiaradwan18 [AT] yahoo.com
}

\begin{abstract}
---
Background: Smart handheld devices are nowadays forming a great impact on people's health. The prolonged use of these devices is known to be associated with musculoskeletal disorders in the upper limb. The aim of this study: was to examine the effect of prolonged usage of tablets on postural alignment in children.
\end{abstract}

Methods: 60 female children, their age ranged from 7 to 10 years, were participated in this study, and they were randomly divided equally into 2 groups according to the total interrupted time spent using the tablets, reported by their parents. Group (1) those who use tablets less than 3hours per day, and group (2) those who use tablets from 3 to 6 hours per day. Assessments and comparisons between the two groups were applied by using the bio photogrammetric postural analysis to measure the Craniovertebral angle (CVA), The Head tilt angle (HTA), Forward Shoulder Angle (FSA), Thoracic kyphotic angle (TKA), Lumbar lordotic angle (LLA) and Pelvic tilt angle (PTA).

Results: The findings indicated significant differences between the examined groups regarding the CVA, HTA, $\overline{F S A, T K A}$, while there were no significant differences could be recorded relative to LLA and PTA.

\section{Conclusion:}

Prolonged sitting posture for children who use tablets can produce postural alignment changes such as FHP, rounded shoulders and increased kyphosis with predicted other spinal changes at lumbar and pelvic regions and associated forward musculoskeletal disorders.

Keywords---- Smart Handheld devices, Tablets, Musculoskeletal disorders, children, Postural analysis

\section{1- INTRODUCTION}

Smart hand-held devices (SHHD) such as tablets, mobiles, and game players are widely used nowadays among children. Little years ago, the number of users of SHHD had increased progressively throughout the world. This could be, at the current time, due to the sharp increase in smartphone markets, high availability of various models, attractive options, and the cheap prices. The usage of tablets becomes increasingly used in the early childhood settings at home for communications, playing, drawing, and even at schools for education. It could hardly find a child without one of these modern devices.

In one study, a self- report indicates that about two- thirds of students aged from 16-18 years were using tablets more than 4 hours per day weekly, and more than two hours each weekend for nearly one half of them. Some studies revealed a relationship between the usage of these smart devices and the different types of postural and musculoskeletal disorders (1-3).

Normal postural alignment develops when the center of gravity of different spinal segments come in line with each other (4). Good posture is always combined with the least strain produced on both active and passive spinal structures (5). Good sitting posture is the ability to produce the least muscular force to control the relation between different body parts and to keep balance (6). 
Concerns about poor postures and musculoskeletal problems related to the prolonged use of SHHD devices also raised. Poor postures in adults have been correlated with many health problems such as chronic neck and back pain, headaches, digestive disorders, respiratory and cardiovascular disorders (7-10).

Because of small screens, it has been suggested that most people are not assuming good posture while using their SHHD, because they tend to utilize their devices from closer distances, and they sit with their heads bent forward, without forearm and back support (11). College student's postures had been evaluated during typing and revealed that ninety one $\%$ of them had neck flexion while typing (12).

Several studies investigated the outcome of display positioning on electrical activity of neck and shoulder muscles, and also the relation between the neck, shoulder pain and the increased time spent in internet browsing[2,13,14].

It is generally established that neck, shoulder, and many musculoskeletal disorders usually result from the very low monitor positions. Tablet as one of the SHHD is associated with more neck flexion, head tilting, scapular protraction, asymmetry of the spine, flexion and elevation of shoulders, and higher neck muscle activity (15). The increased static neck and shoulder muscles loading associated with poor positions will contribute to neck pain and will cause many postural changes such as forward head posture (FHP), rounded shoulders, and thoracic kyphosis. Sustained FHP can cause exhaustion, pain, injury to cervical spinal vertebrae, muscles, and ligaments and, inconsequent, to the whole spine (16).

Some studies revealed the relation between the cervicothoracic and the thoracolumbar regions during sitting postures (17-19). But most of the recent studies have concentrated on the head and neck postures instead of the whole spine during SHHD usage. So, It was important in this study to examine the whole spinal postures.

And although, the increase in the number of children using tablets, little researchers investigated the effects of the extensive usage of these devices on their postures. Our aim in this study was a trial to fill this research gap by investigating the effects of prolonged time usage of tablets on posture in children. Based on our outcome results, advice and interventions could be designed to prevent adverse effects and to promote health in the future.

\section{2- METHODOLOGY}

\section{1: Subjects}

Sixty female children were selected from governmental schools in Al Kharj City, Kingdom of Saudi Arabia. They ranged in age between (7-10) years old with mean ages (8.75 \pm 0.9$)$ and (9.1 \pm 0.6$)$ for both group 1 and 2 respectively. Their height ranged from $(123-138 \mathrm{~cm})$ with mean height $(132.4 \pm 5.3)$ and $(129.2 \pm 5.9)$ for group 1 and 2 respectively. They were randomly divided equally into 2 groups according to the total interrupted times spent using tablets, reported by their parents. Group (1) those who use tablets less than 3 hours per day, group (2) those who use tablets from 3 to 6 hours per day. The study was applied after signing a consent form by their parents, which is approved by the ethical guidelines of Prince Sattam Bin Abdulaziz University and in accordance with that established in the Declaration of Helsinki.

\section{Inclusive criteria:}

Children were included if they were using tablets for at least 1year directly before the research study, and they were daily using the tablet for at least 2 hours per day.

\section{Exclusive criteria:}

Children were excluded if they had: congenital spinal deformities like kyphosis or scoliosis, cervical fracture or trauma, cancer, lung diseases like asthma or chronic bronchitis, congenital neurological or orthopedic diseases, unstable cardiac conditions; and if they had undergone abdominal or thoracic surgeries.

\section{2: Methods}

The posture was evaluated by means of biophotogrammetric analysis which is a valid and a reliable method (20,21). Six postural variables described by Han-suk et al. (22) and Lunes et al. (23)were measured. They are as following:

(1) Craniovertebral angle (CVA) It refers to the amount of forward head posture. It is formed between the horizontal line, and the line connecting the $7^{\text {th }}$ cervical vertebra $(C 7$, the apex) with the tragus. The smaller that angle, the more forward the head position, and if the angle was less than $50^{\circ}$, the child was considered to have FHP (24).

(2) The Head tilt angle (HTA) It is also called the gaze angle, and it represents how much the flexion or extension of the cervical spine. The angle is formed between the line connecting the tragus (apex) to the canthus of the eye and the horizontal line passing through the tragus (the greater the angle is, the more is the extension of the head).

(3) Forward Shoulder Angle(FSA) It is used as an index for shoulder roundedness. It is point of intersection between the line joining the acromion process and $\mathrm{C}$, and the horizontal line passing through the acromion process. It was 
considered that the individual has rounded shoulders, if the angle was less than $52^{\circ}(25)$. The smaller the angle, the more forward shoulder position, in relation to the cervical spine.

(4) Thoracic kyphotic angle (TKA)Which is the angle of intersection of the two perpendiculars to the lines passing through $1^{\text {st }}$ Thoracic(T1) and through T12 vertebrae (the more of that angle, the more is the kyphotic posture).

(5) Lumbar lordotic angle (LLA)That is the angle of intersection of the two perpendiculars to the lines passing through $1^{\text {st }}$ lumbar (L1) and through L5 vertebrae (the more of that angle, the more is the lordotic curve).

(6) Pelvic tilt angle (PTA)That is the angle of intersection of the line connecting anterior superior iliac spine (ASIS, apex) and posterior superior iliac spine (PSIS) with the horizontal line passing through ASIS (the greater the angle is, the greater the anterior pelvic tilt will be).

Biophotogrammetric postural analysis:

The protocol for measurement was applied according to Falla et al.(18), as the anatomic points of C7,T1, T12,L1, L5,ASIS, PSIS, tragus, canthus, the sternal notch, and the acromion process were all marked with small foam balls covered with reflective foil filament and double-sided adhesive tape to be fixed on the skin.

Each child was exposing her neck and trunk, wearing a surgical cap to cover her hair, bared feet, and with a looking forward direction. From the lateral view in a standing position, all the pictures were captured and then assessed by the same researcher. The digital camera (Sony® Cybershot 8 megapixels), was fixed an adjustable height tripod stand, placed at 2 meters distance from the child, and at the level of the external auditory meatus. Photos were processed through a photogrammetric analysis (SAPO® software for postural assessment) that is reliable and provides quantifiable measurements after determining the coordinates of the anatomical points on the photographs $(26,27)$.

\section{3: Statistical analysis:}

Statistical analysis was applied using Statistical Package for Social Sciences (SPSS) version 16.0 (SPSS Inc., Chicago, USA). The data collected were analyzed by using t- test to examine the differences in results in both groups and to apply comparison between groups. Pearson's correlation coefficient and regression analysis of the measured variables was also calculated. Statistical significance was established for values of $\mathrm{p}<0.05$.

\section{3- RESULTS}

The baseline characteristics of groups (1) and (2) are presented in table (1) as mean \pm SD of age, height, and mass. The preliminary mean values were matched and there were no significant differences between them.

Table (1) Baseline characteristics of children in groups(1) and (2)

\begin{tabular}{llll}
\hline Characteristics & $\begin{array}{l}\text { Group (1) } \\
\text { mean } \pm \text { SD }\end{array}$ & $\begin{array}{l}\text { Group (2) } \\
\text { mean } \pm \text { SD }\end{array}$ & P- value \\
\hline Age (years) & $8.75 \pm 0.9$ & $9.1 \pm 0.6$ & 0.22 \\
Height (cm) & $132.4 \pm 5.3$ & $129.2 \pm 5.9$ & 0.12 \\
mass (kg) & $43.6 \pm 5.9$ & $41.3 \pm 2.3$ & 0.17 \\
\hline
\end{tabular}

Table 2 showed that the CVA was statistically and significantly decreased with a more FHP in group 2 compared to group 1. For the HTA, a greater tilting was noted in group 2 showing also a more FHP and indicating larger flattening of upper cervical spine compared to group 1.

The statistical analysis with the paired t-test showed a significant difference in measurements of FSA and TKA between both groups. A lesser FSA and greater kyphotic angle were recorded in group 2.

On the other side, there were no significant differences could be observed in the mean values of LLA and PTA between both groups. 
Table (2) Comparison between the mean values of postural parameters in both groups:

\begin{tabular}{|c|c|c|c|}
\hline Parameters & $\begin{array}{l}\text { Group (1) } \\
\text { mean } \pm \text { SD }\end{array}$ & $\begin{array}{l}\text { Group (2) } \\
\text { mean } \pm \text { SD }\end{array}$ & $P$ value \\
\hline $\operatorname{CVA}\left({ }^{\circ}\right)$ & $48 \pm 2.7$ & $46.2 \pm 2.2$ & $0.02 *$ \\
\hline HTA $\left(^{\circ}\right)$ & $16.1 \pm 5.7$ & $19.7 \pm 5.3$ & $0.04 *$ \\
\hline FSA $\left(^{\circ}\right)$ & $49.3 \pm 3.1$ & $47.2 \pm 3.4$ & $0.04 *$ \\
\hline TKA $\left({ }^{\circ}\right)$ & $32.2 \pm 7.3$ & $37.6 \pm 8.6$ & $0.03^{*}$ \\
\hline LLA $\left(^{\circ}\right)$ & $34.7 \pm 5.1$ & $38.4 \pm 6.7$ & 0.05 \\
\hline PTA $\left(^{\circ}\right)$ & $12.3 \pm 1.7$ & $13.6 \pm 2.4$ & 0.05 \\
\hline
\end{tabular}

p- value $<0.05$. $*($ significant difference $)$

\section{4- DISCUSSION}

A large number of children spend long periods of time sitting at home using their tablets. The human posture is not designed to stay for prolonged times in sitting position. In addition, sitting with a posture is a great problem as it will cause muscle fatigue, muscle imbalance and spinal immobility over time.

When the posture is kept repeatedly in a wrong habitual alignment, this body image will be inserted in the brain, and it will result in an abnormal posture with deformed musculoskeletal structures such as muscles, joints, and ligaments (28).

The results in group 2 showed that the prolonged tablet usage was associated with a more flexed spine than in group 1. Children had been seen to flex their necks up to $20^{\circ}$ or more, the matter that makes the gravitational forces on the neck muscles to be three to five times higher, putting them at risk of discomfort or injury in the future. That risk is increased by increasing the duration of tablet exposure (29).

CVA and HTA are seen to be affected by the tablet position. This indicates that postural changes due to tablet usage are representative of complicated cervical spine changes.

For CVA, a smaller angle is an index for more FHP (24). The mean CVA values obtained here were $\left(48^{\circ}\right)$ and $\left(46.2^{\circ}\right)$ in group 1 and 2 respectively which are significantly different, and at the same time, less than the normal . These were similar to the mean values in one study of the association between postural alignment and upper quadrant pain in high school students. The authors found smaller CVA values ranged from $39^{\circ}-46^{\circ}$ were considered the cause of FHP and upper quadrant pain (30). These results come in agreement with the conclusion that neck flexion angle was greater and CVA was smaller, during tablet use than for desktop and notebook typing [31,32]. Therefore, the tablet users would be at great risk to develop neck pain due to combined factors of poor posture, long duration, and frequency of usage.

HTA is one of the measurements indices to the cervical spine alignment. The overall mean values of HTA in group 2 was low enough, indicating significant tilting in head and FHP. The mean values obtained of both groups in this study were considered above the normal values recommended by De Wall et al.(33). They mentioned for the HTA to be normal, it has to be less than $15^{\circ}$. Also, these more than normal mean values come matched with the mean values got by Chansirinukoret al. (34) in their study for severity of FHP. Their study showed mean values of $\left(16.3^{\circ}\right)$ indicating moderate FHP.

FHP leads in turn to upper cervical spine extension and lower cervical spine flexion. This new alignment increases the lower cervical lordosis in association with a decreased or flattened upper cervical spine curvature (35).

FSA is an angle that gives a measure of the amount of shoulder roundedness. Both groups' FSA mean values in this study come similar to those found in other two studies for evaluating shoulder protrusion, giving that smaller angles indicate forward shoulders $(36,30)$. The average FSA obtained ranged from $\left(47^{\circ}\right.$ to $\left.49^{\circ}\right)$ revealing significant difference between group 1 and 2, showing more rounded and forward shoulders in group 2.

Posture of upper limbs during tablet usage, meaning that FSA, may also impose a risk to the musculoskeletal system in the future. Shoulder flexion more than $25^{\circ}$ was shown to be a risk factor for symptoms in neck and shoulders in adults (37).

Shortened chest muscles due to increased kyphosis showed by increased values of TKA can cause the shoulders to fall forward and thus placing excessive pressure on the upper back. The muscle imbalance generated between the tight chest and lengthened upper back is considered as a common cause of rounded shoulders, and this adds more strain on the upper back musculoskeletal structures. The problem is pronounced by further hunching over during sitting. 
Again, thoracic kyphosis and also FSA have a biomechanical relation to the cervical angle. It should be thought about the more strain added to the neck muscles, fascia, ligaments, joints and capsules with more forward shift of head and shoulders as this could easily accelerate discs degenerations. According to the fact that, for every inch the head is shifted forward, it could place an additional 10 pounds of pressure on the musculoskeletal structures in the cervical region $(15,38)$.

In this research work, kyphosis and FSA have significantly increased in group 2 more than in group 1. It can be interpreted that there is a dependency of the kyphotic posture, rounded shoulders, and FHP as each factor can affect the other. This comes in line with the study of Quek et al. (39) who concluded that FHP increases with increased kyphosis, and also with Szeto et al. (40) who showed that neck changes are resulted from the forward shoulder posutre.

Although the LLA and PTA were significantly indifferent between both groups, increased lumbar lordosis and anterior pelvic tilting are both expected in the future because of prolonged sitting posture. Sitting position causes anterior pelvic tilt, which applies shortening of the iliopsoas muscles. The problem is that in prolonged sitting, the muscles stay shorter than usual even in standing up. The posture compensates by tilting the pelvis anteriorly and in turn, it puts a large strain on the lumbar region resulting in muscle spasms, progressive degeneration of intervertebral disc and back pains in the future. The limitation of this study was that we did not consider other variables including male children and other age groups. We should research considering those variables in the future.

\section{5- CONCLUSION}

It can be concluded that the more time is spent, the more changes in neck region can occur, the more rounded shoulders and kyphosis would be present. The findings of our study are useful to Increase parents' and children's awareness of the associated postural changes resulting from prolonged poor sitting. Also, they can be used in educating children the proper sitting postures, postural correction exercises, and suitable time periods to be spent using their tablets which are important issues to avoid consequent musculoskeletal disorders when being adults.

\section{6- CONFLICTS OF INTEREST}

No potential conflict of interest reported in relation to this article.

\section{7- ACKNOWLEDGMENTS}

The authors would like to express their appreciation to all patients who participated in this study for their cooperation.

\section{8- FUNDING}

All work of this study was conducted in the outpatient clinic at the Faculty of Applied medical sciences, Prince Sattam bin Abdulaziz University, Kingdom of Saudi Arabia. It was not funded, in whole or in part.

\section{9- REFERENCES}

1. Werth AJ, Babski-Reeves K: Effects of Portable Computing Devices on Posture, Muscle Activation Levels and Efficiency, Applied Ergonomics; 45(6), pp. 1603-1609, 2014.

2. Berolo S, Wells RP, Amick BC: Musculoskeletal symptoms among mobile hand-held device users and their relationship to device use: a preliminary study in a Canadian university population. Appl Ergon; 42: 371-378, 2011.

3. Hakala PT, Rimpela AH, Saarni LA, Salminen JJ: Frequent computer-related activities increase the risk of neckshoulder and low back pain in adolescents. Euro J of Public Health; 16(5):536-41,2006.

4. Griegel-Morris P, Larson K, Meuller-Klaus K, Oatis CA: Incidence of common postural abnormalities in the cervical, shoulder, and thoracic regions and their association with pain in two age groups of healthy subjects. Phys Ther.; 72:425-431, 1992.

5. Geldhof E, Cardon G, De Bourdeaudhuij I, Daneels L, Coorevits P, Vanderstraeten G, De Clerq D: Effects of back posture education on elementary schoolchildren's back function. Eur Spine J.; 16:829-839, 2007.

6. Olsson K, Blomkvist A, Beckung E: Pressure mapping as a complement in clinical sitting analysis in children during activity. Adv Physiother; 10:76-84,2008.

7. Cote P, Cassidy JD, Carroll L: The factors associated with neck pain and its related disability in the Saskatchewan population. Spine; 25(9):1109-17,2000.

8. Lennon J, Shealy CN, Cady RK, Matta W, Cox R, Simpson WF: Postural and respiratory modulation of autonomic function, pain, and health. Am J of Pain Management ; 4:36-9,1994. 
9. Pynt J, Mackey MG, Higgs J.: Kyphosed seated postures: extending concepts of postural health beyond the office. J Occup Rehabil.; 18(1): 35-45,2008.

10. Corlett EN: Sitting as a hazard. Safety Science; 46: 815-821, 2008.

11. Rosenfield M , Bababekova Y, Hue JE, Huang RR: Font size and viewing distance of handheld smart phones. Optometry and Vision Science; 88(7):795-797, 2011.

12. Gold JE, Driban JB, Thomas N, Chakravarty T, Channell V, Komaroff E: Postures, typing strategies, and gender differences in mobile device usage: An observational study. Appl Ergon; 43(2):408-12, 2012.

13. Psihogios JP, Sommerich CM, Mirka GA, Moon SD: A field evaluation of monitor placement effects in VDT users. Applied Ergonomics.; 32(4): 313-325, 2001.

14. Straker L, Burgess-Limerick R, Pollock C, Murray K, NettoK, Coleman J, et al.: The impact of computer display height and desk design on 3D posture during information technology work by young adults. J Electromyogr Kinesiol.; 18(2):336-349, 2008.

15. Ruivo RM, Pezarat-Correia P, Carita AI: Cervical and shoulder postural assessment of adolescents between 15 and 17 years old and association with upper quadrant pain. Braz J Pys Ther.;18(4):364-71, 2014.

16. Bonney RA, Corlett EN.: Head posture and loading of the cervical spine. Appl Ergon; 33: 415-417, 2002

17. Caneiro JP, O'Sullivan P, Burnett A, Barach A, O'Neil D, Tveit O, Olafsdottir K: The influence of different sitting postures on head/neck posture and muscle activity. Man. Ther ;15, 54-60,2010.

18. Falla D, Jull G, Russell T, Vicenzino B, Hodges P: Effect of neck exercise on sitting posture in patients with chronic neck pain. Phys. Ther; 87, 408-417, 2007.

19. O'Sullivan P, Dankaerts W , Burnett AF, Farrell GT, Jefford E, Naylor CS., O'Sullivan KJ: Effect of different upright sitting postures on spinal-pelvic curvature and trunk muscle activation in a pain-free population. Spine (Phila Pa1976) 31, E707-E712, 2006.

20. Sacco ICN, Alibert S, Queiroz BWC, Pripas D, Kieling I, Kimura AA, et al: Reliability of photogrammetry in relation to goniometry for postural lower limb assessment. Rev. Bras. Fisioter.;11(5):411-7,2007.

21. Ruivo RM, Pezarat-Correia P, Carita AI: Intrarater and interrater reliability of photographic measurement of upper body standing posture of adolescents. J Manipulative PhysioTher.;38(1):74-80,2015.

22. Han-suk Lee, Hyung-Kuk Chung and Sun-wook Park: The analysis of severity of forward head posture with observation and photographic method. J. Korean Soc Phys Med.; 10(3):227-235, 2015.

23. Lunes DH, Monte-Raso W, Santos CBA, Castro FA, and Salgado HS: Postural influence of high heels among adult women: analysis by computerized photogrammetry. Rev Bras Fisioter.; 12(6): 454-9. 2008.

24. Diab AA, Moustafa IM.: The efficacy of forward head correction on nerve root function and pain in cervical spondylotic radiculopathy: a randomized trial. Clin Rehabil. Apr;26(4):351-61,2012.

25. Thigpen CA, Padua DA, Michener LA, Guskiewicz K, Giuliani C, Keener JD, et al: Head and shoulder posture affect scapular mechanics and muscle activity in overhead tasks. J ElectromyogrKinesiol. Aug; 20(4):701-9, 2010.

26. Priscila W, Eliane CC, Jovana M, Juliana CS, Maria ET: Craniocervical posture: cephalometric and biophotogrammetric analysis. Braz j oral Sci.;11(3):416-421, 2012.

27. Salahzadeh Z, Maroufi N, Ahmadi A, et al: Assessment of forward head posture in females: observational and photogrammetry methods. J Back Musculoskelet Rehabil.;27(2):131-9,2014.

28. Pamela KL, Norkin CC: Joint structre \& Function: A comprehensive analysis. Philadelphia. F.A. Davis Company,2011.

29. Vasavada AN, Nevins DD, Monda SM, Hughes E, Lin DC: Gravitational demand on the neck musculature during tablet computer use. Ergonomics 58,990-1004,2015.

30. Brink Y, Crous LC, Louw QA, Grimmer-Somers K, Schreve K: The association between postural alignment and psychosocial factors to upper quadrant pain in high school students: a prospective study. Man Ther; Dec;14(6):64753,2009 .

31. Albin T, McLoone H: Effect of tablet tilt and display conditions on user posture, performance and preferences. Proceedings of the 10th Applied Ergonomics Conference; March 13-15; Dallas, TX: Institute of Industrial Engineers, 2007.

32. Shin G, Hegde S: User-preferred position of computer displays: effects of display size. Hum Factors.; 52(5): 574$585,2010$.

33. De Wall M, Van Riel MPJM, Aghina JCFM, Burdorf FA, Snijders CJ: Improving the sitting posture of CAD/CAM workers by increasing VDU monitor working height. Ergonomics.;(35):427-36,1992.

34. Chansirinukor W, Wilson D, Grimmer K, Dansie B: Effectsof backpacks on students: measurement of cervical and shoulder posture. Aust J Physiother. Jan;47(2):110-6, 2001.

35. Kuo YL, Tully EA, GaleaMP: Video analysis of sagittal spinal posture in healthy young and older adults. Journal of Manipulative and Physiological Therapeutics.; 32(3): 210-5,2009.

36. Van Niekerk SM, Louw Q, Vaughan C, Grimmer-Somers K, Schreve K: Photographic measurement of upper body sitting posture of high school students: a reliability and validity study. BMC Musculoskelet Disord. Jan;9:113,2008. 
37. Marcus M, Gerr F, Monteilh C, Ortiz DJ, Gentry E, Cohen S, Edwards A, Ensor C, Kleinbaum D: A prospective study of computer users; ii. Postural risk factors for musculoskeletal symptoms and disorders. American journal of industrial medicine; 41, 236-249,2002.

38. Lau KT, Cheung KY, Chan KB, et al: Relationships between sagittal postures of thoracic and cervical spine, presence of neck pain, neck pain severity and disability. Man Ther.;15(5):457-62,2010.

39. Quek J, Pua YH, Clark RA, et al: Effects of thoracic kyphosis and forward head posture on cervical range of motion in older adults. Man Ther.;18(1):65-71,2013.

40. Szeto GP, Straker L, Raine S: A field comparison of neck and shoulder postures in symptomatic and asymptomatic office workers. Appl Ergon.;33(1):75-84, 2002. 